\title{
EL USO DE LA FUERZA CONTRA ACTORES NO ESTATALES. UNA CRÍTICA A LA TEORÍA "UNWILLING OR UNABLE" DESDE EL DERECHO INTERNACIONAL VIGENTE
}

\author{
Autor: Jorge Rodríguez Rodríguez \\ jrodriguez@myuax.com \\ Universidad Alfonso X el Sabio
}

\begin{abstract}
Resumen
La aparición de nuevas formas de terrorismo internacional ha traído consigo la necesidad de repensar el sistema de seguridad colectiva. La gravedad de los ataques perpetrados por actores no estatales ha propiciado que los Estados víctimas de estos ejerzan la fuerza contra ellos, en aplicación de la teoría, así conocida, unwilling or unable. Esta teoría implica un replanteamiento de ciertas estructuras jurídicas ya consolidadas en el ordenamiento jurídico internacional, tales como el derecho de legítima defensa o la atribución del comportamiento de particulares a Estados. Este artículo pretende analizar el porqué de la aparición de esta teoría, así como de los debates que la misma ha abierto entre la doctrina internacionalista.
\end{abstract}


Palabras clave: uso de la fuerza; legítima defensa; terrorismo; atribución del comportamiento.

\section{The use of force against non state actors. A critique to the "unwilling or unable" doctrine}

\section{Abstract}

The emergence of new forms of terrorism in international level, made necessary to rethink the system of collective security. The gravity of these kind of attacks executed by non-state entities, gave the opportunity to the State victims to justify the use of force against them, in accordance with the unwilling or unable theory. This theory consists on the reconsideration of various legal norms which supposed to be consolidated in the international legal system, such as the self-defense and the attribution of conduct to a State. The present article consists on the analysis of the reasons for the emergence of the above theory and of the debates that had originate on the international doctrine.

Key words: use of force; self - defense; terrorism; attribution of conduct to a State.

Fecha de recepción: 09/05/2019

Fecha de aceptación: 24/06/2019

\section{INTRODUCCIÓN}

Que la globalización es un fenómeno que ha modificado todo aquello que nos es conocido es algo ya más que notorio; analizado en la teoría y contrastado en la práctica. Las nuevas formas de comunicación, conexión y cooperación entre Estados, personas físicas y jurídicas han supuesto un cambio copernicano en la forma en la que vivimos. Ningún ámbito de la sociedad se ha mostrado indiferente ante los nuevos retos ${ }^{1}$ que supone una nueva forma de vivir y entender el mundo. No obstante, entre los desafíos a los que nos enfrentamos, lamentablemente, hemos de incluir una nueva amenaza que ha hecho plantearnos, como comunidad internacional, distintas cuestiones que hasta su aparición difícilmente podríamos, si quiera, aventurar.

1 Véase, acerca de los nuevos desafíos a los que se enfrenta la comunidad internacional: López Martín (ed.) \& Chinchón Álvarez (coord.) (2016). 
En efecto, las nuevas formas de terrorismo internacional cuentan con unas particularidades que hacen que el sistema consagrado en la Carta de Naciones Unidas, y centralizado alrededor del Consejo de Seguridad, resulte sumamente difícil de mantener en su situación actual y que ha hecho poner en cuestión la eficacia de determinados principios estructurales del Derecho Internacional, como la prohibición de amenaza y uso de la fuerza, pilar sobre el que descansa todo el sistema de seguridad colectiva de Naciones Unidas.

Retomando aquí las palabras de Pierre Marie Dupuy, la Carta de Naciones Unidas refleja una suerte de contrato social internacional (citado por Regueiro, 2012, p. 58), en cuyo artículo 2 quedan consagrados los principios que inspiran la actuación de los Estados que la componen. Teniendo presente la letra del artículo 2.4 de la Carta de Naciones Unidas, y su obligada contraparte del artículo 2.3, la legítima defensa se presenta como una de las muy tasadas excepciones mediante las cuales los Estados pueden incumplir la prohibición de usar la fuerza en el arreglo de sus controversias, sin que ello comporte la comisión de un hecho internacionalmente ilícito. La misma redacción del artículo 51 de la Carta de Naciones Unidas así lo explicita: "Ninguna disposición de esta Carta menoscabará el derecho inmanente de legítima defensa, individual o colectiva".

Empero, la realidad demuestra que el artículo 2.4 de la Carta de Naciones Unidas ha sufrido una derrota constante (Rodríguez, 1974, p. 209) desde 1945 y que el contenido del artículo 51 del mismo tratado está sujeto, como afirma Rodríguez Carrión, a interpretaciones subjetivas por parte de cada Estado debido, principalmente, "al grado de desarrollo y maduración de cada sistema jurídico" (1974, p. 209). Ello no puede implicar, en ningún caso, poner en cuestión la vigencia o consideración de ius cogens de la prohibición de uso de la fuerza, pero sí, considero, abre un importante debate acerca del modo en el que los Estados -sobre todo aquellos con mayor influencia internacional-aplican estos mismos estándares a una realidad no prevista al tiempo de redacción de la Carta y en lo que respecta aquí a la regulación del derecho de los Estados a la legítima defensa.

Muestra de estas nuevas interpretaciones a las que nos referimos sobre la aplicación de este derecho inmanente, por poner aquí solo un ejemplo, tenemos el caso de que numerosos Estados respaldaran la posibilidad de que Israel pudiera responder en legítima defensa a los ataques perpetrados por Hezbollah y Hamás, independientemente de que se trataran de actores no estatales ${ }^{2}$. $\mathrm{O}$, como sostiene

\footnotetext{
2 Ante este ejemplo concreto, Raphaël Van Steenberghe ha concluido que: "Such a recognition is very remarkable. First, it sharply contrasts with the traditional responses of the international community to past Israeli interventions, which were generally limited to condemning Israel for an unnecessary and/ or disproportionate military response. Second, the declarations in which states recognized the right of Israel to defend itself against attacks launched from Lebanon or Gaza were unambiguous. Finally, these
} 
Antonio Remiro Brotóns, en su análisis sobre la respuesta de Estados Unidos en supuesta legítima defensa tras los atentados del 11 de septiembre:

“(...) si ahora Estados Unidos (y Gran Bretaña) aducen legítima defensa y todas las instituciones con atribuciones para pronunciarse otorgan, habrá que reconocer que ahora a eso, esto es, a la operación militar desencadenada como consecuencia de atentados terroristas imputados a actores no estatales (Al-Qaida) con la complicidad de gobiernos no reconocidos (talibanes) de Estados miembros de las Naciones Unidas (Afganistán) se le llama legítima defensa. Políticamente es explicable que Estados y órganos de Naciones Unidas se agarren a la legítima defensa para no afrontar la engorrosa realidad de que el sistema de seguridad colectiva diseñado por la Carta se ha venido abajo" (2001, p. 155).

En efecto, la legítima defensa constituye una de las posibilidades donde los Estados pueden ejercer la fuerza, sin que ello suponga un quebrantamiento de la norma imperativa que la prohíbe. Una posibilidad a la que los Estados pueden recurrir siempre que, habiendo sufrido un ataque previo por parte de un tercer Estado, cumplan los ya consabidos requisitos de provisionalidad, inmediatez, necesidad, proporcionalidad e informen debidamente al Consejo de Seguridad. La disyuntiva a la cual nos enfrentamos, y a la que responde este artículo, es a la continua aplicación de una regulación centrada en el Estado (la Carta de Naciones Unidas) a una realidad donde parte de las principales amenazas actuales no provienen (ya) solo de su lado, sino también de actores no estatales.

No pretendo realizar aquí un extenso análisis de los requisitos anteriores para definir en profundidad el concepto de legítima defensa dentro del Derecho Internacional, pues para ello hay otros trabajos que se han encargado de ello en detalle ${ }^{3}$, lo que aquí se estudiará será comprobar si los anteriores estándares en legítima defensa pueden ser mantenidos en el estado actual de la comunidad internacional, específicamente, a los casos donde el atacante no es un Estado, sino un grupo terrorista, y sin erosionar el espíritu encarnado en el artículo 2.4 de la Carta de Naciones Unidas, propiciando de esta manera la comisión de un uso ilegítimo de la fuerza. Para ello trataremos de analizar en profundidad una de las teorías bajo la cual, actualmente, ciertos Estados han justificado sus intervenciones en un tercero para actuar contra un grupo armado. Esta teoría conocida como unwilling or unable presenta una interesante perspectiva que, en ciertos aspectos, pudiera parecer contraria al texto

declarations were expressed unexpectedly by a large number of states, especially in the case of the Israeli intervention in Lebanon in 2006" (2010, p. 193).

${ }^{3}$ Entre los numerosísimos trabajos que han venido analizando este particular desde innumerables perspectivas, podemos consultar con interés los siguientes: Remito Brotóns (2001), González Vega (2001), Pérez González (2003), Ruys \& Verhoeven (2005), Hellmann \& Regueiro (2015), Reinold (2011), Cervell Hortal (2017), Green (2009), Regueiro (2012). 
de la Carta de Naciones Unidas, como así lo han afirmado ciertos sectores doctrinales; sentencia a la cual intentaremos dar respuesta en las próximas páginas.

\section{EL PORQUÉ DE LA APARICIÓN DE LA TEORÍA UNWILLING OR UNABLE}

La aparición de nuevas normas jurídicas es algo que no es ajeno al ordenamiento internacional, ni a cualquier cuerpo normativo; pues no habrá ordenamiento más inservible que aquel que no es capaz de adaptarse a las necesidades y características de la sociedad que ha de cumplirlo. En concreto, la expansión del derecho de legítima defensa es ciertamente un debate de gran interés para los Estados, pues estamos ante una de las pocas oportunidades en las que puede ejercerse el uso de la fuerza en amparo del Derecho Internacional; lo cual ofrece un escenario muy proclive para un entendimiento más bien laxo de los elementos necesarios para su ejercicio. Este debate, lícito a todas luces, encuentra su punto de anclaje en una realidad hasta hace poco desconocida, y a la cual el Derecho Internacional debe dar una respuesta: la aparición de nuevas formas de terrorismo internacional.

Como punto de partida ineludible, habremos de hacer énfasis en la posición de la norma que prohíbe el uso de la fuerza dentro del ordenamiento jurídico internacional. Según José Antonio Perea Unceta (2004) "la paz se concibe en el sistema de las Naciones Unidas como un bien, o un valor, común a todos los Estados" (p. 106); en consecuencia, la prohibición de uso de la fuerza no cuenta, únicamente, con la consideración de derecho consuetudinario, sino de norma imperativa de Derecho Internacional general (Perea Unceta, 2004, p. 106). De esta sentencia se desprende la reflexión de Raquel Regueiro al afirmar que "la legítima defensa fue concebida como una excepción a la prohibición expresada en el artículo 2.4; por lo tanto, se trata de un derecho excepcional, de un privilegio" (2012, p. 132)4. Así lo ha afirmado también el Relator Especial Ago:

"The absolutely indispensable premise for the admission of the idea of self-defence, with its intrinsic meaning, into a particular system of law is that the system must have contemplated, as a general rule, the prohibition of the indiscriminate use of force by private subjects, and hence admits the use of force only in cases where it would have purely and strictly defensive objectives, in other words, in cases where the use of force would take the form of resistance to a violent attack by another. Accordingly, if self-defence is to be regarded as an exceptional circumstance precluding the wrongfulness of conduct inconsistent with a general obligation to refrain from the use of force,

${ }^{4}$ También, en el sentido de una excepción a la regla general del art.2.4 de la Carta (Pozo Serrano, 2016, p. 160). 
it would be meaningless to think of it in the context of a system of law to which this obligation is unknown" (1980, párr. 83).

En lo que aquí nos ocupa, y más allá de otros debates ya clásicos sobre la necesaria comisión de un ataque armado previo para ejercer la legítima defensa, será el requisito de que el mismo provenga de un Estado el que ha venido reinterpretándose - ampliándose. $\mathrm{O}$, dicho de otro modo, si un ataque proveniente de un actor no estatal (como, por ejemplo, un grupo terrorista), sin conexión alguna con un Estado, puede activar el contenido del artículo 51 de la Carta de Naciones Unidas. Y es que las últimas décadas nos han mostrado una realidad en la cual no solo los Estados tienen la capacidad para atacar un territorio extranjero y producir un daño tal que el Estado víctima tenga la necesidad de devolver el ataque para defenderse ${ }^{5}$. Ciertamente, desde los atentados del 11 de septiembre de 2001 no han sido pocas las propuestas que giraban alrededor de nuevos paradigmas en legítima defensa y atribución del comportamiento; teorías que amplían el concepto de este derecho inmanente y que lo actualizan conforme a las necesidades de los Estados víctimas. En efecto, según Oriol Casanovas, parece que el sentir general es "que la comunidad internacional quiso ampliar la noción de legítima defensa y considerar los ataques terroristas como susceptibles de enmarcarse en el concepto de 'ataque armado' del art. 51 de la Carta" (2004, p. 133) ${ }^{6}$. En contraposición, tampoco son pocos los que ponen el foco en que por la propia singularidad de aquellos actores no estatales que cometen estos actos - fuera del amparo de un Estado - es sumamente discutible que pueda ser de aplicación el contenido del artículo 51 de la Carta. Así, por ejemplo, el Relator Especial para las Ejecuciones Extrajudiciales, Sumarias o Arbitrarias, Philip Alston, considera que: "sólo en muy contadas ocasiones un actor no estatal que no esté vinculado con algún Estado estará en disposición de llevar a cabo el tipo de ataques armados que darían lugar al derecho a utilizar la fuerza con carácter extraterritorial" (Consejo de Derechos Humanos, 2010, p. 13).

Teniendo presente lo anterior, en los últimos lustros hemos asistido al estiramiento de la regla de legítima defensa hasta límites insospechados, donde en su nombre podían cometerse los más horrendos crímenes, quedando las reglas (indiscutibles e innegociables) de proporcionalidad, necesidad, inmediatez y ataque previo en el fondo de lo razonable; siendo, por ello, estos supuestos ataques defensivos contra actores no estatales en el territorio de un tercero un uso ilegítimo de la fuerza. Haciendo nuestras las palabras de Luís Ignacio Sánchez Rodríguez, a

${ }^{5}$ Estos grupos como Al Qaeda o el ISIS han sido definidos por Michael Scharf como «massive wealth, sophisticated training and organization, and access to destructive weaponry» (Scharf, 2016, p. 52).

${ }^{6}$ Para una opinión no tan favorable a esta evolución de la legítima defensa véase Remiro Brotóns (2001), Como señala este autor, "lo que se propone como interpretación amplia o extensiva del concepto de legítima defensa acaba desnaturalizándolo" (p. 157). 
colación de las consecuencias derivadas de la aplicación de la así llamada legítima defensa preventiva, pero que pudiéramos aplicar a nuestro marco de discusión: "los pretendidos supuestos de legítima defensa preventiva constituyen general intervención en los asuntos internos de otro Estado o, puro y simplemente, supuestos de agresión o represalias armadas" (Sánchez, 2005, p. 194).

En definitiva, la realidad es que, hasta el momento presente, no contamos con un asidero jurídico internacional convencional o consuetudinario sólido que autorice el uso de este derecho contra un ataque perpetrado por un grupo armado no estatal; tal es, también, la última opinión que contamos al respecto por parte de la Corte Internacional de Justicia (CIJ).

Visto todo lo anterior y, en consecuencia, el terreno es propicio para que nuevas realidades jurídicas aparezcan de cara a regular esta situación, ya sea directamente sobre este particular, o ya, como veremos también, sobre otros aspectos del ordenamiento internacional que favorecen este mismo objetivo. Así, la teoría unwilling or unable representa una de estas propuestas: la posibilidad de que un Estado víctima de un ataque perpetrado por un actor no estatal pueda ejercer su derecho a la legítima defensa en el territorio donde se refugia dicho grupo, siempre que considere que el Estado de refugio ${ }^{7}$ no puede o no quiere actuar contra él.

Sin anclaje aún claro y consolidado en el ordenamiento internacional ${ }^{8}$, esta teoría ha sido definida por María José Cervell como "la posibilidad de que un Estado emplee la fuerza en territorio de otro, sin su consentimiento, por su incapacidad o falta de voluntad de frenar a grupos terroristas que desde allí atacan a otros" (2018, p. 77). Por su parte, Ashley Deeks la ha definido como sigue:

"Nonstate actors, including terrorist groups, regularly launch attacks against states, often from within the territory of another state. When a victim state seeks to respond with force to such attacks, it must decide whether to use force on the territory of a state with which it may not be in conflict. International law traditionally requires the victim state to assess whether the territorial state is "unwilling or unable" to suppress the threat itself. Only if the territorial state is unwilling or unable to do so may the victim state lawfully use force" (2012, p. 483).

${ }^{7}$ A los efectos del presente artículo entenderemos por Estado víctima al Estado que ha sufrido el ataque por parte del actor no estatal. Y por Estado de refugio al Estado en cuyo territorio se refugia/tiene su base el actor no estatal que ha atacado al Estado víctima.

${ }^{8}$ Según afirma María José Cervell Hortal (2018) "No aparece en tratado alguno, ni la jurisprudencia la ha acogido, con lo que de momento (...) no puede calificarse sino de propuesta, defendida por algunos Estados y un sector doctrina" (2018, p. 79). A sensu contrario, Michael P. Scharf (2016) es de la opinión de que: "The implication of this newly accepted change in the international law of self-defense is that any State can now lawfully use force against non-state actors (terrorists, rebels, pirates, drug cartels, etc.) that are present in the territory of another State if the territorial State is unable or unwilling to suppress the threat posed by those non-state actors" (p. 53). 
Son varios los trabajos que se han encargado de analizar esta teoría desde varios prismas ${ }^{9}$, poniendo, en ocasiones, las Resoluciones del Consejo de Seguridad 1373 y 1368 como punto de partida a la aparición de una suerte de connivencia de la comunidad internacional, sobre todo desde 2001 (Scharf, 2016, pp. 52-53; Van Steenberghe, 2010, p. 207; Reinold, 2011, p. 284), con la posibilidad de que un Estado pueda usar la fuerza en el territorio donde se encuentra el grupo no estatal que previamente ha atacado contra él. En concreto, la Resolución 1368 de 12 de septiembre de 2001 expresaba que el Consejo de Seguridad "está dispuesto a tomar todas las medidas que sean necesarias para responder a los ataques terroristas perpetrados el 11 de septiembre de 2001 y para combatir el terrorismo en todas sus formas". Así como exhortar a la comunidad internacional a "prevenir y reprimir los actos de terrorismo", debiendo de "rendir cuentas (...) los responsables de prestar asistencia, apoyo o abrigo a los autores, organizadores y patrocinadores de estos actos".

Así, varias son las aristas afectadas por esta nueva doctrina pues implica la reformulación de varios aspectos ya regulados y consolidados consuetudinaria y jurisprudencialmente dentro del ordenamiento jurídico internacional, como a continuación veremos.

\section{REQUISITOS PARA ACTIVAR LA TEORÍA UNWILLING OR UNABLE}

Siendo la finalidad última de la teoría unwilling or unable la justificación del uso de la fuerza de un Estado víctima de un ataque por parte de un actor no estatal en el Estado donde este tiene su refugio, los asideros jurídicos de los que se sirve serán:

- La existencia del derecho de los Estados a ejercer su derecho en legítima defensa tras la comisión de un ataque armado proveniente de actores no estatales.

- La permanencia del actor no estatal que cometió el ataque en el Estado de refugio, ya sea debido a la imposibilidad fáctica de combatirlo o a simplemente tolerarlo, activa el derecho del Estado víctima a usar la fuerza en el territorio de éste por la atribución del comportamiento del actor no estatal al Estado de refugio.

A continuación, pasaremos a desarrollar ambos requisitos de forma individualizada.

${ }_{9}$ Cervell Hortal (2018), Scharf (2016), Ahmed (2013a), Ahmed (2013b), Deeks (2012). 


\section{LA COMISIÓN DE ATAQUES ARMADOS POR PARTE DE ACTORES NO ESTATALES Y SUS CONSECUENCIAS EN DERECHO INTERNACIONAL}

De cara a analizar esta nueva concepción, será necesario atender a dos factores: la gravedad/entidad con la que cuenta el ataque, y su consecuente atribución a un actor no estatal, y la posible existencia de una norma jurídica internacional (en forma consuetudinaria, convencional o dentro de una Resolución del Consejo de Seguridad) que faculte a los Estados a ejercer un ataque armado contra un actor no estatal.

\subsection{La calificación de ciertas acciones cometidos por actores no estatales como "ataques armados"}

La concepción clásica de la legítima defensa en Derecho Internacional sigue lo establecido en el artículo 21 del Proyecto de artículos sobre responsabilidad del Estados por hechos internacionalmente ilícitos (Proyecto de artículos), en conjunto con el artículo 51 de la Carta, de los cuales se colige que el ataque armado previo ha de provenir de un Estado. Es decir, en caso de que no sea posible atribuir el ataque a un Estado, según la teoría general, será jurídicamente imposible calificar, en su caso, un posterior uso de la fuerza por su parte como en legítima defensa.

A comienzos del s.XXI muy pocos eran los que defendían que los actores no estatales pudieran cometer ataques armados (Dinstein, 2001, pp. 213-215; Tomuschat, 1999, 215-216). De hecho, el propio Consejo de Seguridad negó en 1985 que los ataques cometidos por Israel en Túnez, lugar donde tenía su refugio la Organización para la Liberación de Palestina, fueran perpetrados en legítima defensa ${ }^{10}$. En este sentido, la CIJ en su sentencia de 2005 sobre el caso de la República Democrática del Congo contra Uganda, a colación de la correcta aplicación de la legítima defensa, interpretó que: "el artículo 51 de la Carta puede justificar el uso de la fuerza en legítima defensa sólo en marco de los estrictos límites en él establecidos. Esta disposición no permite el uso de la fuerza por un Estado para proteger lo que considere sus intereses de seguridad más allá de esos parámetros"11 (Corte Internacional de Justicia, 2005, párr.148).

En efecto, el significado y finalidad de la legítima defensa es otorgar una primera y provisional protección al Estado cuando este sea víctima de un ataque armado cometido por un tercero. Por tanto, nuestro primer análisis debe estar

\footnotetext{
10 Resolución del Consejo de Seguridad 573 de 1985.

11 Véase, un análisis de esta sentencia en: Chinchón Álvarez (2010).
} 
dedicado a definir este concepto, de cara a analizar si dentro del significado del mismo pudieran quedar amparados los ataques cometidos por actores no estatales.

Siguiendo el significado del término "agresión", afianzado en la Resolución 3314 de la Asamblea General de las Naciones Unidas, tendrán dicha consideración acciones tales como:

a) La invasión o el ataque por las fuerzas armadas de un Estado del territorio de otro Estado, ó [sic] toda ocupación militar, aun temporal, que resulte de dicha invasión o ataque, o toda anexión, mediante el uso de" la fuerza, del territorio de otro Estado o de parte de él;

b) El bombardeo, por las fuerzas armadas de un Estado, del territorio de otro Estado, o el empleo de cualesquiera armas por un Estado contra el territorio de otro Estado;

c) El Moqueo de los puertos o de las costas de un Estado por las fuerzas armadas de otro Estado;

d) El ataque por las fuerzas armadas de un Estado contra las fuerzas armadas terrestres, navales o aéreas de otro Estado, o contra su flota mercante o aérea;

g) La utilización de fuerzas armadas de un Estado, que se encuentran en el territorio de otro Estado con el acuerdo del Estado receptor, en violación de las condiciones establecidas en el acuerdo o toda prolongación de su presencia en dicho territorio después de terminado el acuerdo;

f) La acción de un Estado que permite que su territorio, que ha puesto a disposición de otro Estado, sea utilizado por ese otro Estado para perpetrar un acto de agresión contra un tercer Estado;

g) El envío por un Estado, o en su nombre, de bandas armadas, grupos irregulares o mercenarios que lleven a cabo sotos de fuerza armada contra otro Estado de tal gravedad que sean equiparables a los actos antes enumerados, o su sustancial participación en dichos actos.

Ciertamente, pese a que tradicionalmente las anteriores acciones han sido cometidas por Estados, la realidad es que los actores no estatales cuentan actualmente con la capacidad para, si bien no perpetrar exactamente las mismas acciones, sí atentar de forma que la gravedad del ataque sea análoga a cualquiera de ellas. Es decir, lo importante será poner en el foco en la entidad de la acción que se comete, de cara a evaluar si la misma cuenta con la categoría de ataque armado, en el sentido del artículo 51 de la Carta de Naciones Unidas.

En este sentido, para la CIJ no cualquier acto de uso de la fuerza da lugar a ejercer el derecho de legítima defensa, sino solo aquellos "más graves". Así, por ejemplo, habremos de interpretar cada caso de forma individualizada, teniendo en cuenta lo ya sentado por el juez Kooijmans en su voto particular a la sentencia de la CIJ del caso de la República Democrática del Congo contra Uganda: "si 
los ataques por grupos irregulares, dados su escala y sus efectos, hubieran tenido que ser clasificados como un ataque armado si se hubieran llevado a cabo por las fuerzas armadas regulares, no hay nada en el lenguaje del art. 51 de la Carta que impida al Estado víctima ejercer su derecho inmanente de legítima defensa" (Corte Internacional de Justicia, 2005, p. 314).

De esta forma, no todo acto catalogado como terrorista dará pie a la activación de la legítima defensa. Esto es, no convertiremos acción terrorista en sinónimo de ataque armado. Siguiendo a Raquel Regueiro y Jaqueline Hellman (2015):

"the relation between terrorism and the right of self-defence must be based on the intensity of the attack, seen from the perspective of individual acts attributable to a State. It should be assessed whether the terrorist acts rise to the level of sufficient intensity and severity to qualify an armed attack within the meaning of Article 51. That implies that its intensity and effects are such that they would be classified as an armed attack if they were carried out by regular armed forces" (p. 151).

En este mismo sentido, acerca de centrar nuestra atención en la gravedad de cada ataque cometido, más allá de la subjetividad de quien lo comete, el Relator Especial para las Ejecuciones Extrajudiciales, Sumarias o Arbitrarias, Philip Alston, ha afirmado que:

"the reality is that it will only be in very rare circumstances that a non-state actor whose activities do not engage the responsibility of any State will be able to conduct the kind of armed attack that would give rise to the right to use extraterritorial force (...) sporadic, low intensity attacks do not rise to the level of armed attack that would permit the right to use extraterritorial force in self-defence, and the legality of a defensive response must be judged in light of each armed attack, rather than by considering occasional, although perhaps successive, armed attacks in the aggregate" (Consejo de Derechos Humanos, 2010, párr .40-41).

Igualmente, Chatham House, dentro de sus Principios de Derecho internacional sobre el uso de la fuerza por los Estados en legítima defensa, consideró que: "There is no reason to limit a state's right to protect itself to an attack by another state. The right of self-defence is a right to use force to avert an attack. The source of the attack, whether a state or a non-state actor, is irrelevant to the existence of the right" (Chatham House, 2005, p. 11).

Como prueba que respalde a esta afirmación, puede ser alegada la declaración del por entonces Primer Ministro francés, Manuel Valls, tras el primer bombardeo de Francia en Siria contra santuarios del DAESH: "Bombardearemos cada vez que nuestra seguridad nacional esté en juego", alegando el artículo 51 de la Carta de Naciones Unidas (El País, 2015). De esta forma, se constata que, actualmente, lo 
relevante una vez un Estado sufre un ataque armado es evaluar el daño sufrido, más allá de la subjetividad de quien la comete.

De todo ello se colige que en aquellos casos donde un actor no estatal comete un ataque armado, el mismo podrá ser atribuido directamente a éste si, en aplicación del contenido del artículo 8 del Proyecto de artículos, resulta imposible su atribución a un Estado y siempre que el daño cometido fuese calificado como tal si hubiera sido cometido por un actor estatal. Esta posibilidad ya ha sido contrastada dentro de otros escenarios, como son los del mantenimiento de la paz y la seguridad internacionales dentro del marco del Capítulo VII de la Carta de Naciones Unidas, que ejemplifica perfectamente la Resolución 811 sobre Angola de 1993 del Consejo de Seguridad, donde condena las violaciones del Acuerdo de Paz por la guerrilla de la UNITA y "que considerará responsable a cualquiera de las partes que se niegue a participar en ese diálogo y ponga así en peligro todo el proceso, y que estudiará la posibilidad de adoptar todas las medidas apropiadas de conformidad con la Carta de Naciones Unidas". Así, el interrogante al que nos lleva todo lo anterior sería: si las acciones de los actores no estatales pueden contribuir al desencadenamiento de la aplicación de los artículos 40, 41 y 42 de la Carta, ¿también podrían suponer la aplicación del artículo 51? Teniendo en cuenta, por tanto, que actualmente los actores no estatales cuentan con capacidad suficiente para cometer un ataque armado, la existencia de varias teorías que dan respuesta a este interrogante las trataremos a continuación.

\subsection{El ejercicio del derecho a la legítima defensa contra actores no estatales en aplicación del Derecho Internacional}

Teniendo presente lo analizado hasta ahora, esto es, la capacidad contrastada de los actores no estatales para cometer ataques armados, los debates abiertos actualmente sobre el particular -debido, sobre todo, a los ataques yihadistas de las últimas dos décadas- presentan la posible atribución del derecho de los Estados a actuar en legítima defensa contra todos los ataques armados sufridos, con independencia de quién los haya cometido. La finalidad, de este modo, sería llegar a un escenario donde pudiera aplicarse la máxima "a mismos hechos, mismas consecuencias"; posición cada vez más común entre Estados y doctrina, tal y como nos recuerda Felipe Gómez Isa:

"(...) hay algunos que defienden que los ataques de Al-Qaeda, incluso teniendo en cuenta el conjunto de todos los ataques lanzados por esta red terrorista desde principios de los años noventa, no constituyen una ofensiva militar a gran escala (...) ésta no es la postura mayoritaria ni entre la doctrina ni entre los Estados" (2015, p. 76). 
En efecto, la corriente clásica apunta a que el artículo 51 de la Carta será aplicado y aplicable exclusivamente en ataques armados cometidos entre Estados; al estar incluida esta disposición en un tratado internacional y en consonancia con la posición mantenida por la CIJ en su opinión consultiva sobre la construcción de un muro en territorio palestino ocupado, cuando sentenció que para ejercer el derecho a la legítima defensa será necesario el "ataque armado de un Estado contra otro" (Corte Internacional de Justicia, 2004, párr.139). A contrario sensu, ciertas posturas aluden a que los ataques armados cometidos por actores no estatales darían lugar al derecho de los Estados de actuar en legítima defensa contra los mismos.

Así, y teniendo en cuenta lo analizado en el epígrafe anterior, estos autores proponen, de este modo, una relectura de la letra de la propia Carta. Como representante de esta corriente, Sean Murphy (2002) sostuvo que:

"There is nothing in Article 51 of the U.N. Charter that requires the exercise of self-defense to turn on whether an armed attack was committed directly by another state. Indeed, the language used in Article 2(4) (which speaks of a use of force by one "Member" against "any state") is not repeated in Article 51. Rather, Article 51 is silent on who or what might commit an armed attack justifying self-defense" (p. 50)

Siguiendo una línea parecida, en su voto particular a la opinión consultiva de la CIJ anteriormente mencionada, Rosalyn Higgins abre la puerta a la posible existencia de ataque armados perpetrados por actores no estatal, pues: "no hay nada en el texto del art. 51 que estipule que la legítima defensa solamente opera cuando el ataque armado sea cometido por un Estado" (Corte Internacional de Justicia, 2004, p. 215).

Un paso más allá da, sin embargo, Philip Alston pues alude a un razonamiento altamente compartido entre cierto sector doctrinal: que el ejercicio de la legítima defensa contra actores no estatales es considerado ya un derecho consuetudinario (Consejo de Derechos Humanos, 2010, párr.40). A este respecto, él mismo señala la invocación del artículo 5 del Tratado del Atlántico Norte por parte de la OTAN tras los atentados del 11 de septiembre de 2001, que recoge la legítima defensa colectiva, así como las mencionadas Resoluciones del Consejo de Seguridad 1373 y 1368.

En efecto, la aparición del Estado Islámico ha aumentado el respaldo estatal y doctrinal acerca de esta posibilidad pese a que, como hemos venido comprobando, la CIJ no ha venido compartiendo esta interpretación. En este sentido baste referirse al citado caso de la República Democrática del Congo c. Uganda donde al no poder 
atribuir los ataques sufridos por Uganda al Congo ${ }^{12}$, declinó el derecho de aquel a actuar en legítima defensa (Corte Internacional de Justicia, 2005, párr. 146-147). Pese a ello, Elizabeth Wilmshurst ha afirmado que "In line with the Wall Advisory Opinion this should not be read as prohibiting action in self-defence against non-state actors as such" (Chatham House, 2005, p. 11).

El inicio de esta práctica puede ser fechada en los ataques del 11 de septiembre de 2001 y en la consecuente respuesta de los Estados Unidos contra el Gobierno talibán de Afganistán, en amparo de un supuesto derecho a la legítima defensa. Empero, no solo habremos de centrar nuestra atención en la acción que emprendió Estados Unidos, sino en la reacción de la comunidad internacional. En un análisis sobre este particular, Antonio Remiro Brotóns comienza recordando que, tras la calificación de la respuesta armada de Estados Unidos en suelo afgano como legítima defensa "todo el mundo al parecer se ha sentido cómodo" (Remiro Brotóns, 2001, p. 154); entre ellos, la OTAN, como ya hemos aludido, en invocación del artículo 5 del Tratado del Atlántico Norte; las partes del Tratado Interamericano de Asistencia Recíproca; el Consejo Europeo Extraordinario ${ }^{13}$; el por entonces Secretario General de Naciones Unidas, Kofi Annan, quien aludió en su declaración de 8 de octubre de 2001 al "derecho inherente a la legítima defensa individual o colectiva de acuerdo con la Carta de las Naciones Unidas. Siguiendo este contexto los Estados afectados han dispuesto sus acciones militares actuales en Afganistán"14; o el mismo Consejo de Seguridad.

12 "It is further to be noted that, while Uganda claimed to have acted in self-defence, it did not ever claim that it had been subjected to an armed attack by the armed forces of the DRC. The "armed attacks" to which reference was made came rather from the ADF. The Court has found above (paragraphs 131-135) that there is no satisfactory proof of the involvement in these attacks, direct or indirect, of the Government of the DRC. The attacks did not emanate from armed bands or irregulars sent by the DRC or on behalf of the DRC, within the sense of Article 3 ( $\mathrm{g}$ ) of General Assembly resolution 3314 (XXIX) on the definition of aggression, adopted on 14 December 1974. The Court is of the view that, on the evidence before it, even if this series of deplorable attacks could be regarded as cumulative in character, they still remained non-attributable to the DRC. For all these reasons, the Court finds that the legal and factual circumstances for the exercise of a right of self-defence by Uganda against the DRC were not present. Accordingly, the Court has no need to respond to the contentions of the Parties as to whether and under what conditions contemporary international law provides for a right of selfdefence against large-scale attacks by irregular forces. Equally, since the preconditions for the exercise of self-defence do not exist in the circumstances of the present case, the Court has no need to enquire whether such an entitlement to self-defence was in fact exercised in circumstances of necessity and in a manner that was proportionate. The Court cannot fail to observe, however, that the taking of airports and towns many hundreds of kilometres from Uganda's border would not seem proportionate to the series of transborder attacks it claimed had given rise to the right of self-defence, nor to be necessary to that end".

13 Tal y como recoge Antonio Remiro Brotóns, la reacción de Consejo Europeo fue más comedida al no citar expresamente el supuesto derecho a la legítima defensa que estaba ejerciendo Estados Unidos, sino que alegó que: "sobre la base de la Resolución 1368 del Consejo de Seguridad, es legítima una respuesta estadounidense” (Remiro Brotóns, 2001, p. 154).

14 Disponible en: Secretary General, Statements and messages, Doc. SG/SM/7985-AFG/149: https:// www.un.org/press/en/2001/sgsm7985.doc.htm 
En efecto, indudablemente las Resoluciones del Consejo de Seguridad 1373 y 1368 , que sirvieron de condena a los atentados del 11 de septiembre, se han interpretado, en ocasiones, como una suerte de respaldo jurídico internacional a actuar en legítima defensa contra ataques armados de actores no estatales ${ }^{15}$. No obstante, no podemos si no contraponernos a esta afirmación. Siguiendo la interpretación de Raquel Regueiro al respecto, en primer lugar, el Consejo de Seguridad se limitó simplemente a calificar dichas acciones como de amenaza para la paz y la seguridad internacionales, obviando mencionar el término ataque armado, posición que sí hubiera tenido, en cambio, una evidente incidencia en la aplicación del artículo 51. En segundo lugar, este órgano no posee competencia alguna a la hora de interpretar el contenido de la legítima defensa, de modo que no puede crear una nueva concepción del mismo, lo que competería a la misma CIJ (Regueiro, 2012, p. 316). De este modo, la actuación del Consejo de Seguridad se limitó a poner el acento en la peligrosidad que las acciones terroristas suponen para la paz y la seguridad internacionales, algo indudablemente indiscutible. Al contrario de lo que pudiera entenderse, estas Resoluciones no primaron el derecho a la legítima defensa como primer medio necesario para la revocación de actos de terrorismo, ni mucho menos auguraron la cristalización de un nuevo derecho consuetudinario.

Por otro lado, de entre las voces más contundentes a favor de la aparición de un nuevo derecho consuetudinario de ejercer la legítima defensa contra ataques armados perpetrados por actores no estatales, Raphaël Van Steenbergue respalda su aparición tras un análisis de una reciente práctica estatal ejemplificada con dos casos muy paradigmáticos, como son la incursión de turcos en Iraq en 2008 o la intervención de Israel en Gaza o el Líbano. Para este autor: "These cases evidence that a state need not necessarily be substantially involved in attacks by non-state actors in order for the victim state to respond in self-defence" (Van Steenbergue, 2010, p. 206). La supuesta aparición de esta práctica también ha sido alegada por Theresa Reinold: "The terrorist challenge (especially the prospect of nuclear-armed jihadists) has thrown into sharp relief the need to develop a somewhat broader understanding of the concept of self-defense than the one enshrined in the UN Charter" (2011, p. 3).

15 De hecho, es menester apuntar que una de las críticas que se alegaron en contra de la opinión consultiva de la $\mathrm{CIJ}$ con respecto a la construcción de un muro en territorio palestino ocupado vino de mano de que la misma, y su lectura e interpretación del artículo 51 de la Carta de Naciones Unidas, en la que se calificaba como ataque armado solo los ataques cometidos de un Estado contra otro "would be inconsistent with the language of Article 51, and the current state of international law", en alusión a que obviaba la posibilidad de los actores no estatales, demostrada tras los atentados del 11 de septiembre, de cometer ataques armados (Wedgwood, 2005, p. 58). 
Para muchos autores, la comentada práctica estatal iniciada tras el 11 de septiembre del 2001 tiene un punto de inflexión en el actual contexto sirio ${ }^{16}$, valiéndose también de la posición tomada por el Consejo de Seguridad en su Resolución 2249, el cual, así han interpretado, avala la respuesta armada contra ataques de actores no estatales, pues según afirma Scharf (2016): "the international community's response to ISIS in Syria has provided the final push necessary to bring the Grotian Moment to fruition (...). Despite its ambiguity, Resolution 2249 will likely be viewed as confirming that use of force in self-defense is now permissible against non-state actors where the territorial state is unable to suppress the threat that they pose" (p. 53).

En la existencia o no de una práctica generalizada desde la anterior fecha parece estar la clave. Como ya comentamos, aquí aluden no solo a que habremos de fijarnos en el uso de la fuerza cometido por Estados contra actores no estatales, sino en cuál ha sido la reacción de los demás Estados de la comunidad internacional a colación de este comportamiento. En efecto, según ciertos autores interpretan, la ausencia de una protesta específica por parte de la generalidad de la comunidad internacional acerca de estas actuaciones conforma el bloque doctrinal que defiende dicha posición, debido a que las reticencias de ciertos Estados no han sido dirigidas hacia la subjetividad del objetivo del ataque, sino por razones sobre la proporcionalidad de la respuesta (Van Steenbergue, 2010, pp. 192-193).

Sin embargo, resulta cuanto menos cuestionable la existencia de una práctica generalizada acerca de la posibilidad de usar la fuerza en legítima defensa contra ataques de actores no estatales con refugio en terceros Estados. Más allá de que los Estados que la respaldan se encuentran entre las principales potencias internacionales (Estados Unidos, Israel, Rusia o Francia), otros como España o Reino Unido no alegaron derecho alguno a la legítima defensa cuando fueron víctimas de ataques armados por parte de actores no estatales. Por ello, creemos que es difícil de respaldar un comportamiento generalizado, constante y uniforme a este respecto. Y es que, siendo la prohibición de uso de la fuerza una obligación de no hacer, aún la generalidad de los Estados de la comunidad internacional la siguen cumpliendo, pese a que los ataques cometidos por las grandes potencias sigan contando con mayor relevancia y transcendencia internacional.

${ }^{16}$ La importancia de la posición que los Estados han tomado en el conflicto sirio para la generación de una posible nueva norma de derecho consuetudinario también ha sido compartida por María José Cervell: "El DAESH ha influido, qué duda cabe, respecto de la posible consolidación de la norma que permitiría la legítima defensa contra actores no estatales. Las reacciones de los Estados parecen afirmar que, al menos, ya hay un grupo de Estados (los más de 60 que conforman la Coalición Internacional que contra él lucha) convencidos, pues no en vano esa legítima defensa es la base para sus acciones en Irak y en Siria. (...). Tal y como la sociedad internacional evoluciona y cómo se comportan sus actores, quizá no sea descabellado pensar que esa opción ha llegado para quedarse" (2018, pp. 86-87). 
Pero, en la práctica, estos siguen siendo una excepción a un comportamiento generalizado. Así, por ejemplo, autoras como Pilar Pozo Serrano, entienden que, en lo referido a la existencia de una práctica estatal que ampare el derecho de legítima defensa contra actores no estatales: "No existen la uniformidad ni la coherencia necesarias para afirmar la cristalización de una nueva interpretación de la noción de legítima defensa, pero sí parece haberse extendido una postura más flexible en cuanto a la admisibilidad de la legítima defensa frente a usos de la fuerza por actores no estatales que no son atribuibles a un Estado" (Pozo, 2016, p. 162).

En definitiva, habremos de descartar la existencia de un derecho consuetudinario que respalde el ejercicio de la legítima defensa contra actores no estatales. Pese a ello, en el siguiente epígrafe analizaremos si el factor que comporta que el actor no estatal haya atacado desde el Estado de refugio implica algún tipo de responsabilidad para con este.

\section{LA PERMANENCIA DEL ACTOR NO ESTATAL EN EL ESTADO DE REFUGIO Y LA ATRIBUCIÓN AL ESTADO DE SU COMPORTAMIENTO}

Llegados a un estadio donde no puede ser amparado el uso de la fuerza contra actores no estatal en ejercicio de la legítima defensa, la siguiente opción que habremos de contemplar como posible alude a la posibilidad de que el Estado de refugio pudiera estar comprometiendo su responsabilidad derivada de la comisión de un ataque armado, cometido por el actor no estatal desde su territorio. Deberemos, por tanto, analizar la posible atribución de ese acto al mismo Estado de refugio.

Como inicio de nuestro análisis, deberemos de retrotraernos, de nuevo, al 11 de septiembre de 2001. Tras los ataques sufridos por Estados Unidos, el por entonces Presidente, George Bush, sentenció: "we will make no distinction between the terrorists who committed these acts and those who harbor them" (citado en Scharf, 2016, p. 29). En efecto, con estas declaraciones estábamos presenciando la equiparación del contenido del artículo 8 del Proyecto de artículos (dirigir/controlar el ataque) a otras acciones del Estado como "dar cobijo" o, simplemente, "albergar" a aquellos que realizaron los ataques: "[f]rom this day forward, any nation that continues to harbor or support terrorism will be regarded by the United States as a hostile regime" (citado en Scharf, 2016, p. 30).

La aplicación de la teoría unwilling or unable supone la aceptación de que la simple permanencia del grupo armado en el territorio del Estado de refugio puede llegar a considerarse como una connivencia de éste con la actuación de aquel, independientemente de la falta de un nexo directo con sus actividades. De esta forma, vemos como el contenido del artículo 8 del Proyecto de artículos queda 
diluido. En efecto, en los últimos tiempos hemos asistido a una cierta flexibilización de las exigencias sobre atribución del comportamiento recogidos en la anterior disposición, de modo que cada vez el necesario nexo entre Estado y actor no estatal es más superfluo y difuso.

Partiendo de una base general, y a efectos de atribuir el comportamiento de particulares a un Estado, la CIJ en el mencionado caso de las Actividades Militares y Paramilitares en Nicaragua sentenció que:

"Tras examinar los hechos, la Corte consideró probado que, en una fecha de fines de 1983 y comienzos de 1984, el Presidente de los Estados Unidos de América autorizó a una dependencia del Gobierno de los Estados Unidos a que tendiera minas en los puertos nicaragüenses; que a primeros de 1984 fueron tendidas minas dentro o cerca de los puertos de El Bluff, de Corinto y de Puerto Sandino, ya fuera en las aguas internas de Nicaragua o en su mar territorial, por personas pagadas por esa dependencia o siguiendo instrucciones de ella, bajo la supervisión y con el apoyo logístico de agentes de los Estados Unidos" (Corte Internacional de Justicia, 1986, pp. 95-96).

Esta jurisprudencia de la CIJ, en la que se requieren comportamientos ligados a actos de "supervisión", "instrucción" o "apoyo", exige, por tanto, que el Estado dirija o tenga un control efectivo de la situación. De esa forma en situaciones donde la incidencia del Estado es meramente incidental o periférica, es decir, que escapa a su directo control o dirección, la misma en ningún caso pudiera serle atribuida (Ruys y Verhoeven, 2005, p. 300). No obstante, más allá de estas situaciones, la Sala de Apelaciones del Tribunal Penal Internacional de la ex Yugoslavia en el caso Tadic concluyó la necesidad de un control global (no efectivo) de la situación, subiendo así el umbral necesario para la atribución del hecho: "for the attribution to a State of acts of these groups it is sufficient to require that the group as a whole be under the overall control of the State" (TPIY, 1999, párr. 120) ${ }^{17}$.

${ }^{17}$ La propia CIJ ha criticado la aplicación del control global por parte del Tribunal Penal Internacional para la ex Yugoslavia de la siguiente manera: «It must next be noted that the "overall control" test has the major drawback of broadening the scope of State responsibility well beyond the fundamental principle governing the law of international responsibility: a State is responsible only for its own conduct, that is to say the conduct of persons acting, on whatever basis, on its behalf. That is true of acts carried out by its official organs, and also by persons or entities which are not formally recognized as official organs under internal law but which must nevertheless be equated with State organs because they are in a relationship of complete dependence on the State. Apart from these cases, a State's responsibility can be incurred for acts committed by persons or groups of persons -neither State organs nor to be equated with such organs- only if, assuming those acts to be internationally wrongful, they are attributable to it under the rule of customary international law reflected in Article 8 cited above (paragraph 398). This is so where an organ of the State gave the instructions or provided the direction pursuant to which the perpetrators of the wrongful act acted or where it exercised effective control over the action during which the wrong was committed. In this regard the "overall control" test is unsuitable, for it stretches too far, almost to 
Sea como fuere, la teoría general exige un nexo causal (de intensidad variable, según la jurisprudencia a la que nos refiramos, como hemos visto) entre los actos de los particulares y el Estado a efectos de que se produzca la atribución del hecho ${ }^{18}$; quedando, así, la mera permanencia del grupo en el territorio del Estado de refugio, en un principio, fuera de marco de discusión. En efecto, como hemos comprobado en la sentencia del caso Nicaragua, la Corte ya sostenía que la misma ayuda a fuerzas rebeldes por parte de un Estado mediante el suministro de armas o el apoyo logístico no daba lugar a ejercer la legítima defensa contra ese Estado (Corte Internacional de Justicia, 1986, párr. 195). Ello supone, en consecuencia, que podríamos interpretar que la simple permanencia o, incluso, tolerancia del grupo en el territorio de un tercer Estado no da lugar a atribuirle el ataque, ni mucho menos que dicho comportamiento pudiera ser asimilado a la comisión del mismo. Así, Van Steenberghe afirma que: "It is clear (...) that the mere inability or unwillingness of a state to put an end to the activities of non-state actors on its territory cannot amount to an armed attack by this state under Resolution 3314" (2016, p. 196). En este mismo sentido, Antonio Remiro Brotóns interpretó, sobre el comportamiento del Gobierno talibán tras los atentados del 2001, que:

"Colaborar con una organización terrorista es, desde luego, ilegal, y muy grave; de ahí que todas las actividades ligadas al terrorismo hayan sido calificadas como amenazas a la paz y seguridad internacionales y, atendiendo a esta calificación, el Consejo de Seguridad haya adoptado incluso medidas coercitivas contra Estados y gobiernos renuentes a cumplir sus órdenes fundadas en el capítulo VII de la Carta. Pero la complicidad del régimen talibán, el auxilio, refugio o cualquier clase de apoyo que haya

breaking point, the connection which must exist between the conduct of a State's organs and its international responsibility" (CIJ, 2007, párr. 406).

${ }^{18}$ Más allá de los escenarios generales, dentro del artículo 10 del Proyecto de artículos se contempla uno específico acerca de los comportamientos atribuidos por las acciones de los movimientos de liberación nacional. En estos contextos, los dos primeros párrafos de este artículo establecen: «1. Se considerará hecho del Estado según el derecho internacional el comportamiento de un movimiento insurreccional que se convierta en el nuevo gobierno del Estado. 2. El comportamiento de un movimiento insurreccional o de otra índole que logre establecer un nuevo Estado en parte del territorio de un Estado preexistente o en un territorio sujeto a su administración se considerará hecho del nuevo Estado según el derecho internacional». Más allá de que este trabajo se centre en un régimen general en materia de atribución de comportamiento (en especial, en las situaciones descritas en el artículo 8 del Proyecto de artículos), es menester, por tanto, tener en cuenta la finalidad que persiguen ciertos actores no estatales que puedan tener como objetivo último el control del Gobierno del Estado. Y es que, ante la posibilidad de que tengan éxito, serán estos actores los que habrán de asumir la responsabilidad internacional por los hechos cometidos. Independientemente de lo anterior, el párrafo tercero, contempla la regla general, también aquí aplicable, donde la actuación del movimiento insurreccional, que actúe en el sentido contemplado entre los artículos 4 a 9 del Proyecto de artículos, será atribuida y atribuible al Estado. 
podido prestar a los autores, la organización terrorista Al-Qaida, no basta, según los precedentes conocidos, para plantear la reacción en términos de legítima defensa". (2001, p. 155)

Teniendo esta interpretación presente, otra de las cuestiones directamente relacionadas con este particular reside en que, si bien la permanencia del grupo no da pie a considerarla como un comportamiento que entre dentro de los parámetros del artículo 8 del Proyecto de artículos, sí pudiéramos valorar, en su caso, que se estuviera incumpliendo una obligación de impedir la comisión de un ataque armado contra el Estado víctima. A este respecto, el propio Van Steenberghe ha asegurado que:

"It may be difficult at first glance to imagine that a state could not be held responsible for the attacks directed against another state when these attacks are committed from its territory, given the existence of a general obligation imposed on states to prevent attacks from being committed abroad from their territory (...). This obligation is provided in UNGA Resolution 2625 (XXV). It is also contained in UNGA Resolutions 49/60 (1994) and 1373 (2001), some UNSC resolutions adopted in particular situations and some treaties regulating specific cases. It is almost uncontested that it has a customary nature" (2016, pp. 200-201).

En este supuesto, esta posible omisión del deber de prevención por parte del Estado de refugio, como se desprende de la última jurisprudencia de la CIJ, no equivaldría, en ningún caso, a equiparar su actuación con la comisión de un ataque armado, unido ello, además, a las mismas consecuencias que de ello se derivara (ejercer la legítima defensa); algo desproporcionado a todas luces.

Este deber de prevención fue definido por el Relator Especial Roberto Ago dentro de la Comisión de Derecho Internacional, donde establecía que "El Estado de residencia tiene la obligación de prevenir los actos contrarios al derecho de gentes que pudieran cometer los particulares, así como de aplicar una sanción penal a los autores del acto, una vez que éste ha sido cometido (...) El Estado debe prevenir y penar los actos dirigidos desde su territorio contra la integridad exterior o interior de los Estados extranjeros con los que se encuentra en estado de paz" (1970, p. 126). Sin embargo, esta obligación, como también quedó recogida en la jurisprudencia de la CIJ, no es, en ningún caso, absoluta: "ni la obligación de prevenir esos actos ni la de penarlos revisten un carácter absoluto. La primera sólo se aplica en el marco de una norma general, de una responsabilidad por negligencia, y depende de la situación interna de cada país en una época determinada. El Estado debe dar pruebas de la "debida diligencia"; no está obligado a impedir todo incidente de manera absoluta, 
lo que sería materialmente imposible" (Comisión de Derecho Internacional, 1970, p. 126).

Un caso paradigmático sobre el que vale la pena detenerse brevemente es el referido a los así llamados Estados fallidos, es decir, aquellos que carecen del elemento constitutivo de la organización política y social ${ }^{19}$ (López Martín, 2010, p. 21); una etiqueta que, de hecho, tal y como afirma Ana Gemma López Martín (2010), los Estados rechazan de plano, pues en muchas ocasiones la misma va a acompañada de intervencionismo (pp. 20-21). En estos casos, donde es imposible la obtención de un consentimiento por parte del Estado (fallido) ante la falta de autoridad competente, según la mencionada autora, sería posible una intervención por razones humanitarias ante violaciones masivas y graves de derechos humanos, siempre y cuando estuviera autorizada por el Consejo de Seguridad, por constituir éstas situaciones en las que la paz y la seguridad internacionales están en riesgo. Y es que, según López Martín, ni siquiera en los anteriores contextos la intervención unilateral sería asumible, sino que solo en situaciones de estricto Estado fallido cabría, en su caso, el envío unilateral de ayuda o asistencia humanitaria por parte de terceros Estados, ante la imposibilidad de obtención de consentimiento (López Martín, 2010, p. 37).

Visto esto, la teoría unwilling or unable arguye que el Estado víctima, como forma de comprobar si, verdaderamente, se está actuando contra el grupo no estatal, habrá de evaluar el comportamiento del Estado de refugio en aras de comprobar si éste, en efecto, está emprendiendo acciones dirigidas a acabar con el grupo armado. En caso de que no tenga la predisposición de hacerlo (unwilling) o bien no pueda (unable), el uso de la fuerza en legítima defensa será legítimo. Es, por tanto, necesario que el Estado víctima realice una suerte de test en el cual compruebe la pertinencia del comportamiento del Estado para con sus intereses ${ }^{20}$. Y será precisamente aquí donde encontremos otro de los puntos

19 Según Ana Gemma López Martín, por Estado fallido habría de entenderse: "a aquellas raras situaciones en las que las instituciones que están obligadas a mantener la ley y el orden y a proteger a los ciudadanos y proveerles de servicios básicos dejan de actuar, desaparecen y, en su lugar, el control, la autoridad es ejercida por entidades privadas -clanes, tribus, señores de la guerra-; una situación, por lo demás, que no es temporal sino duradera" (2010, pp. 20-21).

20 Según Ashley Deeks, en este punto podremos encontrar distintos tipos de escenarios: "In the best-case scenario, the territorial state is willing and able to suppress the threat. In that case, the victim state achieves its goal without expending resources, and the territorial state preserves its sovereignty. In contrast, a state that provides direct support to a nonstate actor in its territory with the intent that the actor undertake armed attacks against another state quite clearly is 'unwilling' to suppress the threat posed by that nonstate actor. A state that has very limited military and police forces and no control over broad swaths of its territory almost certainly is 'unable' to suppress a large and sophisticated set of nonstate actors acting in that ungoverned área" (2012, p. 505). 
a analizar que nos plantea esta teoría, pues según Dawood Ahmed, "Alleging that another state is unwilling or unable/ineffective can be a very subjective claim that is open to significant manipulation, particularly because a state's effectiveness to deal with non-state actors may often not be easily observable to other states and thus provides greater room for conflicting and self-serving interpretations" (2013, p. 14).

Por tanto, las preguntas que cabrían hacerse serían: ¿Qué acciones son necesarias que el Estado de refugio lleve irremediablemente a cabo para poder demostrar su determinación de acabar con el grupo no estatal? ¿Sería válida una persecución judicial? Es decir, ¿el comportamiento del Estado a qué debe ir dirigido, a acabar físicamente con el grupo no estatal, o valdría la incoación de un procedimiento penal?

En efecto, según la jurisprudencia de la CIJ en el caso República Democrática del Congo c. Uganda ésta interpretó que el deber de actuación de un Estado orientado a impedir un ataque en su territorio dependerá de las circunstancias de cada caso y de los medios a su disposición. Y que, en cualquier caso, no estamos ante una obligación de resultado (Corte Internacional de Justicia, 2005, párrs.301, 303). Siguiendo en esta línea, no cabría, en consecuencia, imponer un comportamiento homogéneo de resultado (en este caso, se entiende, la eliminación física del actor no estatal) a cualquier Estado; más aún cuando grupos con una entidad suficiente como para atacar en territorios extranjeros suelen refugiarse en Estados débiles con pocos recursos para combatir debidamente sus actuaciones. Y, en consecuencia, si aplicásemos íntegramente lo que respalda esta teoría, estos mismos Estados deberían convivir no solo con lo que supone contar con un grupo terrorista en su propio territorio, sino con las intervenciones armadas de aquellos Estados a los que éste ha atacado. En este mismo sentido, María José Cervell entiende que: "el que la mera tolerancia de grupos irregulares pueda traducirse, si llevan a cabo un ataque armado, en legítima defensa contra ellos, pero en el territorio de un Estado y sin su consentimiento, es, creo, y por más que algunos Estados lo hayan aplicado, aún discutible a la luz del Derecho Internacional. Y, pretender, yendo más allá de la mera tolerancia, que incluso el hecho de no poder hacerles frente sea argumento suficiente para el empleo de la fuerza resulta, si cabe, aún más arriesgado" (Cervell, 2018, p. 89). $\mathrm{Y}$ es que, el interrogante en el que desemboca todo lo anterior será el siguiente: si diésemos por buena la atribución del ataque al Estado de refugio, ¿contra quién se cometería el ataque armado en legítima defensa: contra el Estado o contra el actor no estatal?

La aplicación de la teoría unwilling or unable defiende que la acción se comete, en exclusiva, contra el actor no estatal. Así, por ejemplo, los ataques 
que Francia cometió contra el Estados Islámico en 2015 tenían como objetivo, reproduciendo las palabras del Estado francés, "los santuarios de Daech [sic] en los que se forman aquellos que atacan a Francia” (El País, 2015). Así, el ataque, según lo dictado por unwilling or unable, se producen contra el actor no estatal.

En contraposición, si aplicamos la misma teoría general, comprobamos como el derecho a ejercer la legítima defensa se activa, únicamente, tras la comisión de un ataque armado cometido por un Estado. En consecuencia, la reacción del Estado víctima ha de cometerse, indudablemente, contra el territorio del primero. El elemento de la territorialidad de la legítima defensa no puede obviarse ni siquiera en los supuestos donde el atacante es un actor no estatal; incluso cuando el nexo utilizado para atribuir el comportamiento al Estado de refugio es tan débil como la propia permanencia del grupo en su territorio. También en estos casos el objetivo del ataque armado del Estado víctima será el territorio de un tercer Estado.

En efecto, la principal controversia que plantea esta teoría a este respecto se encuentra en el nexo tan débil y, podríamos decir, inexistente entre el Estado de refugio y el ataque perpetrado por el actor no estatal, pues como hemos comprobado la mera permanencia e, incluso, tolerancia no valdrían para realizar semejante atribución en aplicación del Derecho Internacional. Caso contrario serían aquellas situaciones donde la aplicación del artículo 8 del Proyecto de artículos justifica la unión entre el ataque del actor no estatal y un Estado; será en estos casos donde la respuesta del Estado víctima en legítima defensa contra el territorio del Estado de refugio esté más que justificada. Sin embargo, la teoría unwilling or unable anula o simplifica hasta el extremo la regla de atribución, encontrándonos ante situaciones de auténticas represalias armadas.

Una de las interpretaciones más interesantes que se derivan del elemento de la territorialidad de la legítima defensa será la distinta entidad con la que suelen contar los dos Estados implicados, la víctima y el de refugio, pues acabamos de comprobar que será en su territorio donde se cometerá el ataque, más allá de que el mismo, según la teoría unwilling or unable, vaya dirigido contra el actor no estatal. Así, por ejemplo, esta tabla, realizada por Dawood Ahmed, ilustra la diferente posición que ostentan, normalmente, los Estados víctima y de refugio, al poner el foco en la diferencia de influencia militar y/o económica existente entre ambos; siendo el Estado víctima normalmente una potencia con mayor peso internacional que el Estado de refugio. 
Tabla 1. Tabla elaborada por Dawood Ahmed donde se ilustra la diferente posición que ostentan los Estados víctima y de refugio ${ }^{21}$

\begin{tabular}{|l|l|c|l|c|}
\hline \multicolumn{1}{|c|}{ AÑO } & Estado víctima & Power Rank & Estado de refugio & Power Rank \\
\hline 2001 & Estados Unidos & 2 & Afganistán & 77 \\
\hline 2002 & Rusia & 5 & Georgia & 114 \\
\hline 2003 & Uganda & 80 & $\begin{array}{l}\text { República Demo- } \\
\text { crática del Congo }\end{array}$ & 127 \\
\hline 2003 & Israel & 46 & Siria & 40 \\
\hline $2004-2012$ & Estados Unidos & 2 & Pakistán & 13 \\
\hline 2004 & Rwanda & 104 & $\begin{array}{l}\text { República Demo- } \\
\text { crática del Congo }\end{array}$ & 127 \\
\hline $2006-2008$ & Turquía & 12 & Iraq & 36 \\
\hline 2006 & Israel & 46 & Líbano & 93 \\
\hline 2008 & Colombia & 32 & Ecuador & 71 \\
\hline 2010 & Francia & 10 & Mali & 112 \\
\hline 2011 & Pakistán & 13 & Afganistán & 77 \\
\hline 2011 & Kenia & 65 & Somalia & 110 \\
\hline
\end{tabular}

Fuente: Ahmed (2013, p. 1822)

Esta tabla muestra doce casos, ocurridos desde 2001, donde los Estados víctimas han aplicado la teoría unwilling or unable para atacar, en territorio de Estados de refugio a actores no estatales que atentaron contra ellos. Como puede deducirse, es casi condición sine qua non para el éxito de esta teoría que el Estado víctima tenga una posición de superioridad (aquí denominada power rank ${ }^{23}$ ) sobre el Estado cuya jurisdicción va a violar sin su consentimiento. Algo lógico, pues a nadie se les escapa que sería casi inimaginable ver al ejército de Afganistán entrar en suelo estadounidense sin su consentimiento, persiguiendo a una banda armada

21 Según este autor, "The table is constructed from data available from a common dataset used to measure state capabilities, the Composite Index of National Material Capabilities" (Dawood, 2013, p. 22). Véase, Singer, Bremer \& Stuckey (1972).

22 Según el autor, "The table is constructed from data available from a common dataset used to measure state capabilities, the Composite Index of National Material Capabilities. See J David Singer, Stuart Bremer, and John Stuckey, "Capability Distribution, Uncertainty, and Major Power War" in Bruce Russett ed, Peace, War, and Numbers (Beverly Hills: Sage, 1972) 19”.

23 Según Dawood Ahmed, " 'power' of each state [is] based on a widely used measure of state power in international relations" (2013, p. 22). 
que ha atentado en territorio afgano. No nos extraña el escenario opuesto. La ausencia de alternativas del Estado de refugio para reaccionar en contra de la acción del Estado víctima es, por tanto, una necesidad imprescindible para la aplicación de esta teoría; casi, incluso, un requisito. Y es que, es paradigmático el caso de Pakistán, que ha ostentado la condición de Estado víctima (para actuar en Afganistán) y Estado de refugio (siendo atacado por Estados Unidos).

Igualmente, en los casos donde los Estados que no cuentan con capacidad suficiente para combatir a los actores no estatales y, por tanto, han tenido que sufrir la intervención de potencias extrajeras, el propio Dawood Ahmed se preguntaba sobre la posición de Rusia; Estado que, debido a su extensión territorial, puede que no tenga un control pleno sobre alguna parte remota de Siberia, por tanto, ¿diríamos que Rusia entraría en la categoría de unable? (Ahmed, 2013, p. 15).

En definitiva, podemos hacer nuestras las palabras de este autor cuando afirma que, al final, la aplicación de esta teoría supone un lastre para los intereses de los Estados más débiles, frente a las acciones emprendidas por las potencias militares y económicas en su suelo (Ahmed, 2013, p. 36). Algo que respaldan otros autores, entre ellos Ignacio Roncagliolo, al afirmar que: "El problema de concebir intervenciones legítimas es que a lo largo de la historia y hasta en la actualidad, la intervención se ha dado en un plano de desigualdad entre Estados, de ahí que la existencia de un derecho de intervención, aun condicionado, para parte importante de la doctrina, tendría siempre como titulares a los fuertes y como sujetos pasivos a los débiles" (2015, p. 453).

En conclusión, afirmar la existencia de un nuevo derecho consuetudinario que permita el ejercicio de la legítima defensa contra actores no estatales, debido a la incapacidad o falta de voluntad ${ }^{24}$ de estos para acabar con su actividad, supone, a su vez, una expansión de la facultad de los Estado en la comisión de represalias, sin atender a los parámetros fijados por el Derecho Internacional. El uso de la fuerza en legítima defensa fue concebido como un instrumento provisional, orientado a rebajar las consecuencias de un ataque armado, hasta que el Consejo de Seguridad tomara las riendas de la situación. Empero, la experiencia ha demostrado que el aparente ejercicio de este derecho contra un actor no estatal no ha supuesto en ninguno de los casos un ejercicio provisional, sino que ha sido utilizado como un disfraz que ocultaba la intención de acabar físicamente con el grupo que se ocultaba en un tercer Estado, sin que éste diera

${ }^{24}$ En cualquier caso, la cooperación de un Estado con un grupo terrorista puede suponer el quebrantamiento de una obligación internacional convencional, recogida en varios tratados internacionales contra el terrorismo. 
su consentimiento. $\mathrm{O}$, lo que sería lo mismo, una represalia armada incompatible con la Carta de Naciones Unidas.

\section{CONCLUSIONES Y REFLEXIONES FINALES}

La teoría unwilling or unable supone un intento por parte de ciertos Estados de la comunidad internacional de actualizar y adaptar nuestro ordenamiento jurídico internacional a una nueva realidad, no presente en el momento de adopción de la Carta de Naciones Unidas. Las consecuencias sufridas desde los albores del s. XXI por los ataques provenientes de grupos armados han casi obligado a reinterpretar unos parámetros que fueron consensuados con un objetivo bien definido: que el uso de la fuerza no se convirtiera en la norma. Algo a lo que han intentado contribuir otros hitos de la justicia internacional orientados a fomentar la cooperación entre Estados como la creación de una Corte Penal Internacional.

La ausencia de regulación específica a este respecto es clara: los Estados víctimas de ataques cometidos por actores no estatales, con refugio en un tercero, no pueden usar la fuerza en el territorio de éste, en correcta aplicación de la regulación internacional sobre legítima defensa y de las reglas de atribución del comportamiento, ambas aquí analizadas. Todo ello bajo el manto del artículo 2.4 de la Carta de Naciones Unidas y la prohibición vigente del uso de la fuerza.

En contraposición, la aplicación de esta teoría supone un claro retroceso para el respeto de los mencionados estándares internacionales, vertebradores y esenciales para la coexistencia pacífica de la comunidad internacional. La aplicación de nuevas doctrinas en uso de la fuerza, aún no consolidadas general o convencionalmente, genera graves consecuencias que, lamentablemente, venimos sufriendo en las primeras dos décadas de este nuevo siglo; en muchas ocasiones amparadas por interpretaciones que pretendían ampliar el significado del derecho de legítima defensa. Y es que, en palabras de George Clemenceau, una nación que quiere hacer la guerra está siempre en estado de legítima defensa (Clemenceau, 1930, p. 282).

El abuso de un derecho que nació como respuesta legal a una situación excepcional no puede camuflarse o estirarse a placer de modo que tinte de legitimidad determinadas acciones que de ningún otro modo pudieran llegar a justificarse. Esta lógica supondría dejar la interpretación de la legalidad internacional, de forma unilateral, en manos de los propios Estados donde, cada cual, según sus propias necesidades, cumple o no con sus obligaciones internacionales. Así, haríamos buenas las palabras de Schlomo Ben Ami, ex Ministro de Exteriores israelí, cuando fue preguntado sobre la legalidad del asesinato de Bin Laden a 
manos del ejército estadounidense en suelo pakistaní: "Supongo que la operación no es legal, pero sí es legítima” (El País, 2011).

En efecto, la posible (aunque poco probable) confirmación de la existencia de una norma consuetudinaria que permitiera ejercer el derecho de legítima defensa contra actores no estatales en suelo de terceros Estados, junto con la aceptación de la flexibilización de las normas de atribución del comportamiento, supondrían la extensión hasta límites insospechados de comportamientos que merman la soberanía de los Estados más débiles, a manos de las principales potencias internacionales. No nos es extraño que tanto Estados Unidos como Israel y, actualmente, Francia ${ }^{25}$ hayan sido algunos de sus principales defensores. Y es que su aplicación no haría más que amparar jurídicamente ataques indiscriminados que han supuesto consecuencias catastróficas para los habitantes de esos territorios. Trayendo aquí las palabras de Ashley Deeks, en su análisis sobre los riesgos que pueden derivarse de la aplicación de la teoría unwilling or unable: "Another difficult situation occurs where the victim state hits something other than the entity it planned to hit in the territorial state, because (for example) a missile went off course, or because the victim state had bad intelligence about the location of the target" (Deeks, 2012, p. 533).

Según Rafael García Pérez (2006), son muchos los Estados de la comunidad internacional que han mirado con recelo ciertas prácticas como las defendidas en amparo de la responsabilidad de proteger, la intervención humanitaria o la proliferación nuclear (p. 15). En efecto, pues pese a que las mismas, supuestamente, van orientadas a asistir a los Estados que se encuentran en situaciones donde proliferan violaciones de derechos humanos, por otro lado, esconden un marcado carácter intervencionista el cual pretende, simplemente, defender sus propios intereses. A este respecto, el mencionado autor ha alegado que no nos quedemos simplemente ante aquellas situaciones donde, por ejemplo, Estados Unidos ha intervenido, sino que también comprobemos cuáles han sido las ocasiones donde, ante la comisión de flagrantes y masivas violaciones de derechos humanos cometidas en un tercer Estado, ha quedado impasible:

“(...) no se interviene en aquellos conflictos que no amenazan intereses nacionales directos, o que supongan un riesgo grave e inmediato a la seguridad internacional. Por lo general, tampoco existe una presión significativa por parte de la opinión pública y de las fuerzas políticas internas para ayudar a unas poblaciones de las que todo se ignora y

25 Valga leer la siguiente noticia publicada el 27 de septiembre de 2015 por El País: "Francia alega "legítima defensa" para su primer bombardeo en Siria. "Golpearemos siempre que nuestra seguridad nacional esté en juego". (...) Francia, el primer país de la UE en dar este salto cualitativo, se agarra ahora al artículo 51 de la Carta de Naciones Unidas" (El País, 2015). Disponible en: https://elpais.com/internacional/2015/09/27/actualidad/1443337501_364784.htmlb (Consultado el 3 de abril de 2019). 
que habitan en lugares remotos. En consecuencia, fruto de un cálculo pragmático, los decisores políticos consideraron en todos los casos que los costos económicos, militares y políticos de intervenir para impedir el genocidio superaban con mucho el coste de dejar las cosas como estaban. Y para minimizar el coste moral ante la opinión pública informada, una vez tomada la decisión de no actuar fue manipulada la información sobre los acontecimientos, se destacaron la ambigüedad y las contradicciones de las informaciones disponibles, alegaron desconocimiento sobre los hechos y, llegado el caso, pusieron en marcha los mecanismos diplomáticos (las declaraciones solemnes, las negociaciones complejísimas a muchas bandas, las deliberaciones interminables) para ofrecer la ilusión de que se hacía algo, sin necesidad de tener que intervenir" (García Pérez, 2006, p. 16).

¿Qué opciones tendríamos entonces para prevenir y combatir los ataques perpetrados por actores no estatales? Ana Salinas, en un artículo de 2016, tituló uno de los epígrafes "Privilegiando la represión en detrimento de la prevención" (2016, p. 233) donde puso énfasis en el protagonismo que han tomado las medidas represivas, por encima de otros métodos alternativos orientados a la cooperación internacional (2016, p. 233). En efecto, entre estos métodos, la autora propone, por ejemplo, armonizar una tipificación de las conductas consideradas terroristas, establecer una jurisdicción amplia, reforzar los mecanismos de extradición o reafirmar la asistencia judicial entre Estados (Salinas, 2016, p. 235). Sin embargo, una opción que se propuso ya en 1998, dentro de las negociaciones del Estatuto de la Corte Penal Internacional, fue la futura ampliación de su jurisdicción para juzgar delitos de terrorismo; algo que, debido, entre otras cuestiones, a la falta de un consenso amplio sobre su definición, no fue posible. El establecimiento de una jurisdicción permanente para juzgar los delitos de terrorismo supondría, sin duda, un reforzamiento de la cooperación internacional en torno a prevenir futuros atentados; siempre, claro, que contara con una amplia aceptación por parte de la comunidad internacional, algo que, lamentablemente, no ocurre con la actual jurisdicción de la Corte Penal Internacional.

Sin embargo, como se ha analizado, la ampliación del concepto de legítima defensa no es únicamente la causa única y principal de la propagación de estas represalias, sino que la flexibilización de las causas de atribución del comportamiento de los particulares a los Estados también se ha visto alterada por el impulso de los Estados a reprimir unilateralmente a los actores no estatales que atentan contra ellos. Más allá de lo aquí analizado, se detecta claramente una tendencia que torna inexorablemente hacia una relajación de los criterios generalmente aceptados y amparados por la jurisprudencia de la CIJ; de modo que el escenario actual, en lo concerniente a la actuación de los grupos terroristas, no versa sobre la disputa clásica entre la interpretación de la CIJ (control efectivo) o del Tribunal Penal Internacional para la ex Yugoslavia (control general), sino si la mera 
permanencia del grupo en el territorio del Estado de refugio entraría dentro de los parámetro del artículo 8 del Proyecto de artículos.

Varios Estados y un sector doctrinal ya se han posicionado indiscutiblemente a favor de la aplicación de esta teoría, a la espera de que la CIJ pueda pronunciarse al respecto, en una sentencia que a todas luces se hace necesaria e imprescindible. En nuestro caso, preferimos ser más cautos, toda vez que la expansión del derecho al uso de la fuerza siempre ha de ser vista como una excepción a una norma general que prohíbe imperativamente su uso. La experiencia nos enseña que reconocer un derecho cada vez más amplio a los Estados para el uso de la fuerza puede desembocar en un escenario ingobernable. Y la realidad demuestra tozudamente que nos estamos acercando a dicha situación.

Que estamos en un tablero que no existía hace ochenta años es incontestable; como lo es que el Derecho Internacional ha de actualizarse para intentar ordenarlo. La teoría unwilling or unable es un intento fallido, pues no soluciona el problema, sino que lo agrava, al justificar usos indiscriminados de la fuerza bajo un supuesto manto jurídico internacional alrededor del derecho inmanente de los Estados a la legítima defensa. Primemos pues soluciones de cooperación internacional que aún no se han puesto en marcha; solo así, quizás, no repitamos errores pasados.

\section{BIBLIOGRAFÍA}

Ahmed, D.I. (2013a). Defending Weak States Against the "Unwilling or Unable" Doctrine of Self - Defense. Journal of International Law and International Relations, 9, 1-37.

Ahmed, D.I. (2013b). Rethinking anti - drone legal strategies: questioning Pakistani and Yemeni "consent". Yale Journal of International Affairs, Summer, 1-11.

Casanovas y La Rosa, O. (2004). El principio de prohibición de uso de la fuerza tras el conflicto de Irak 2003. En García Segura, C. y Rodrigo Hernández, A. J. (eds.), El imperio inviable (pp. 125-140). Madrid: Tecnos.

Cervell Hortal, M.A (2018). Sobre la doctrina "unwilling or unable State”, (ipodría el fin justificar los medios?). Revista Española de Derecho Internacional, 1 (1), 77-100.

Deeks, A. (2012). Unwilling or Unable: Toward a Normative Framework for Extraterritorial Self-Defense. Virginia Journal of International Law Association, 52 (3), 483-550.

Dinstein, Y. (2001). War, Agression and Self-Defence. Cambridge: Cambridge University Press.

Chatham House (2005). Principles of International Law on the use of force by States in self-defence, (Elisabeth Wilmshurst) Doc. ILP WP 05/01. 
Chinchón Álvarez, J. (2010). Nuevas oportunidades y viejos circunloquios de la Corte Internacional de Justicia: A propósito de la legítima defensa (preventiva) en la historia de una violación grave de la prohibición del uso de la fuerza que no quiso ser llamada agresión. La sentencia de la Corte Internacional de Justicia de 19 de diciembre de 2005 en el asunto relativo a las actividades armadas en el territorio del Congo (República Democrática del Congo c. Uganda). En Sánchez Rodríguez, L.I., Quel López, F.J. \& López Martín, A.G. (eds.), El poder de los jueces y el estado actual del Derecho Internacional. Análisis crítico de la jurisprudencia internacional (2000-2007), (pp. 419-450). Bilbao: Servicio Editorial de la Universidad del País Vasco.

Comisión de Derecho Internacional, Adición al octavo informe sobre la responsabilidad de los Estados, por el Sr. Roberto Ago -El hecho internacionalmente ilícito del Estado como fuente de responsabilidad internacional. 29 de febrero - 10 y 19 de junio 1980, Documento A/CN.4/318/Add.5 a 7.

Consejo de Derechos Humanos (2010). Report of the Special Rapporteur on extrajudicial, summary or arbitrary executions, Philip Alston, Doc. A/ HRC/14/24/Add.6.

El País (2011, 5 de mayo). Reportaje: La muerte de Bin Laden. El debate sobre la legalidad de la operación. ¿Acto de guerra o ejecución? Disponible en: https:// elpais.com/diario/2011/05/05/internacional/1304546404_850215.html (Consultado el 10 de febrero de 2019).

El País (2015, 27 de septiembre). Francia alega "legítima defensa" para su primer bombardeo en Siria. Disponible en: https:/elpais.com/internacional/2015/09/27/actualidad/1443337501_364784.html (Consultado el 2 de mayo de 2019).

García Pérez, R. (2006). La "responsabilidad de proteger”: Un nuevo papel para Naciones Unidas en la gestión de la seguridad internacional. Revista Electrónica de Estudios Internacional, 11, 1-18.

Gómez Isa, F. (2015). Los ataques armados con drones en Derecho Internacional. Revista Española de Derecho Internacional, 67 (1), 61-92.

López Martín, A.G. (ed.) \& Chinchón Álvarez J. (coord.) (2016). Nuevos retos y amenazas a la protección de los derechos humanos en la era de la globalización. Valencia: Tirant lo Blanch.

López Martín, A.G. (2010). Los Estados "fallidos" y sus implicaciones en el ordenamiento jurídico internacional. En: Cursos de Derecho Internacional y Relaciones Internacionales de Vitoria - Gasteiz (pp. 159-240). Madrid: Thompson Reuters - Aranzadi.

Murphy, S.D. (2002). Terrorism and the Concept of Armed Attack in Article 51 of the U.N. Charter. Harvard International Law Journal, 43 (1), 41-51. 
El uso de la fuerza contra actores no estatales. Una crítica a la teoría "UNWILling or unable"

Perea Unceta, J.A. (2004). Reflexiones sobre las restricciones a la soberanía del Estado en el Derecho Internacional contemporáneo. Anuario jurídico y económico escurialiense, 37, 95-129.

Pozo Serrano, P. (2016). El uso de la fuerza contra el Estado Islámico en Irak y Siria: problemas de fundamentación jurídica. Anuario Español de Derecho Internacional, 32, 141-188.

Regueiro, R. (2012). La legítima defensa en derecho internacional. Madrid: Instituto Universitario General Gutiérrez Mellado - UNED.

Reguiero R. \& Hellman, J. (2015). Targeted killings of suspected terrorists in the light of the right of self-defence. Revue Marroco - Espagnole de Droit International et Relationes Internationales, 3, 143-164.

Remiro Brotons, A. (2001). Terrorismo, Mantenimiento de la Paz y Nuevo Orden. Revista Española de Derecho Internacional, 53 (1-2), 125-171.

Reynolds, T. (2011). State weakness, irregular warfare and the right to self - defense post 9/11, American Journal of International Law, 105 (2), 244-286.

Rodríguez Carrión, A. (1974). Uso de la fuerza por los Estados: interacción entre política y derecho: algunos problemas. Málaga: Organización Sindical.

Roncagliolo Benítez, I (2015). El principio de no intervención: consagración, evolución y problemas en el Derecho Internacional actual. Revista Ius et Praxis, Año 21 (1), 449-502.

Ruys, T. \& Verhoeven, S. (2005). Attacks by Private Actors and the Right Of Self-Defence. Journal of Conflict Eु Security Law, 10 (3), 289-320.

Salinas de Frías, A. (2016). Lucha contra el terrorismo internacional: no solo del uso de la fuerza pueden vivir los Estados. Revista Española de Derecho Internacional, 68 (2), 229-252.

Sánchez Rodríguez, L.I. (2005). Derecho internacional y crisis internacionales. Madrid: Iustel.

Scharf, M. (2016). How the War Against ISIS Changed International Law. Case Western Reserve Journal of International Law, 48 (1), 1-55.

Singer, D., Bremer, S. \& Stuckey, J. (1972). Capability Distribution, Uncertainty, and Major Power War. En Russett, B. (ed), Peace, War, and Numbers (pp. 19 48). Beverly Hills, Estados Unidos: Sage.

Tomuschat, C. (1999). International Law: Ensuring the Survival of Mankind on the Eve of a New Century. General Course of Public International Law. Recueil des Cours de l'Academy de Droit International, 281.

Van Steenberghe, R. (2010). Self - Defense against non - State actor: recent State practice. Leiden Journal of International Law, 23, 183-208.

Wedgwood, R. (2005). The ICJ Advisory Opinion on the Israeli Security Fence and the Limits of Self-Defense. American Journal of International Law, 99 (1), 52-61. 